OPEN ACCESS

Edited by:

Orhan Alimoglu,

Istanbul Medeniyet University Goztepe

Education and Research

Hospital, Turkey

Reviewed by:

Bjørn Steinar Nedrebo

Stavanger University Hospital, Norway

Lunxu Liu,

Sichuan University, China

*Correspondence:

Dong-Qiu Dai

daidq63@126.com;

daidq63@163.com

tThese authors have contributed equally to this work as co-first authors

Specialty section:

This article was submitted to

Surgical Oncology,

a section of the journal

Frontiers in Oncology

Received: 04 April 2019

Accepted: 17 June 2019

Published: 03 July 2019

Citation:

Liu R-J, Zhang C-D, Fan Y-C, Pei J-P,

Zhang $C$ and Dai D-Q (2019) Safety

and Oncological Outcomes of

Laparoscopic NOSE Surgery

Compared With Conventional

Laparoscopic Surgery for Colorectal

Diseases: A Meta-Analysis.

Front. Oncol. 9:597.

doi: 10.3389/fonc.2019.00597

\section{Safety and Oncological Outcomes of Laparoscopic NOSE Surgery Compared With Conventional Laparoscopic Surgery for Colorectal Diseases: A Meta-Analysis}

\author{
Rui-Ji Liu ${ }^{1 \dagger}$, Chun-Dong Zhang ${ }^{1,2+}$, Yu-Chen Fan ${ }^{1}$, Jun-Peng Pei ${ }^{1}$, Cheng Zhang ${ }^{1}$ and \\ Dong-Qiu Dai ${ }^{1,3 *}$ \\ ${ }^{1}$ Department of Gastrointestinal Surgery, The Fourth Affiliated Hospital of China Medical University, Shenyang, China, \\ ${ }^{2}$ Department of Gastrointestinal Surgery, Graduate School of Medicine, University of Tokyo, Tokyo, Japan, ${ }^{3}$ Cancer Center, \\ The Fourth Affiliated Hospital of China Medical University, Shenyang, China
}

Objective: To evaluate the safety and oncological outcomes of laparoscopic colorectal surgery using natural orifice specimen extraction (NOSE) compared with conventional laparoscopic $(\mathrm{CL})$ colorectal surgery in patients with colorectal diseases.

Methods: We conducted a systematic search of PubMed, EMBASE, and Cochrane databases for randomized controlled trials (RCTs), prospective non-randomized trials and retrospective trials up to September 1, 2018, and used 5-year disease-free survival (DFS), lymph node harvest, surgical site infection (SSI), anastomotic leakage, and intra-abdominal abscess as the main endpoints. Subgroup analyses were conducted according to the different study types [RCT and NRCT (non-randomized controlled trial)]. A sensitivity analysis was carried out to evaluate the reliability of the outcomes. RevMan5.3 software was used for statistical analysis.

Results: Fourteen studies were included (two RCTs, seven retrospective trials and five prospective non-randomized trials) involving a total of 1,435 patients. Compared with $\mathrm{CL}$ surgery, the NOSE technique resulted in a shorter hospital stay, shorter time to first flatus, less post-operative pain, and fewer SSIs and total perioperative complications. Anastomotic leakage, blood loss, and intra-abdominal abscess did not differ between the two groups, while operation time was longer in the NOSE group. Oncological outcomes such as proximal margin [weighted mean difference $[\mathrm{WMD}]=0.47 ; 95 \%$ confidence interval $[\mathrm{Cl}]-0.49$ to $1.42 ; P=0.34]$, distal margin $(\mathrm{WMD}=-0.11 ; 95 \% \mathrm{Cl}-0.66$ to $0.45 ; P=0.70)$, lymph node harvest $(\mathrm{WMD}=-0.97$; $95 \% \mathrm{Cl}-1.97$ to $0.03 ; P=0.06$ ) and 5 -year DFS (hazard ratio $=0.84 ; 95 \% \mathrm{Cl}$ $0.54-1.31 ; P=0.45$ ) were not different between the NOSE and CL surgery groups. 
Conclusions: Compared with CL surgery, NOSE may be a safe procedure, and can achieve similar oncological outcomes. Large multicenter RCTs are needed to provide high-level, evidence-based results in NOSE-treated patients and to determine the risk of local recurrence.

Keywords: natural orifice specimen extraction, colorectal diseases, oncological outcomes, post-operative function, totally intra-abdominal laparoscopic surgery, meta-analysis

\section{INTRODUCTION}

Laparoscopic technology has been widely used to treat colorectal cancer (CRC) over the past two decades, and many studies have demonstrated the advantages of laparoscopic surgery and have suggested that it is a less traumatic procedure, with similar oncological outcomes to those of open surgery (13). However, current laparoscopic colectomy is considered to be laparoscopically assisted surgery and not a totally intraabdominal procedure, as it inevitably extends the incision by about $5-8 \mathrm{~cm}$ for specimen extraction and intestinal anastomosis $(4,5)$. Moreover, the laparotomy incision is also a source of post-operative morbidity, such as pain, wound infection, and incisional hernia (6-8).

In an attempt to further reduce surgical trauma, minimally invasive surgery has undergone unprecedented development. Laparoscopic natural orifice specimen extraction (NOSE) surgery is widely regarded as one of the representative new technologies in minimally invasive surgery $(4,9-12)$. It combines the concept of incisionless surgery and laparoscopy to complete intra-abdominal procedures (including exploration, dissection, and resection of lesions) and uses a natural orifice as a delivery route for specimen extraction without laparotomy incision (13). Compared with other minimally invasive techniques, laparoscopic colorectal surgery with NOSE adopts a transabdominal approach, which is more in line with the surgeon's practice and is easier to operate $(5,14-16)$. Recently, several studies have reported that laparoscopic NOSE surgery results in significantly fewer perioperative complications and faster recovery of gastrointestinal function $(4,12)$. However, the safety and oncological outcomes of laparoscopic colorectal surgery with NOSE are unclear. Therefore, we conducted a meta-analysis to determine the safety and oncological outcomes of laparoscopic NOSE surgery compared with conventional laparoscopic (CL) surgery for colorectal diseases.

\section{METHODS}

\section{Search Strategy}

Two independent researchers systematically searched studies in PubMed, EMBASE, and Cochrane databases from January 1990 to September 1, 2018. The search keywords used were "colorectal diseases," "laparoscopic surgery," "natural orifice specimen extraction," "transvaginal specimen extraction," "transanal specimen extraction," and "transrectal specimen extraction." According to the different requirements of each database, the search strategy was correspondingly changed.
Potentially relevant articles were also screened from the references of relevant studies.

\section{Inclusion and Exclusion Criteria}

Studies were included if they conformed to the principle of PICO (S) [participants, interventions, comparisons, outcomes, (study design)] (17). Inclusion criteria were as follows: (1) participants: patients were diagnosed with colorectal diseases, either benign or malignant; (2) interventions: totally intraabdominal laparoscopic colorectal surgery, with the specimen extracted via the rectum, vagina or anus; (3) comparisons: laparoscopic colorectal surgery, with the specimen extracted through the abdominal wall; (4) outcomes: 5-year diseasefree survival (DFS), lymph node harvest, proximal margin, distal margin, operation time, hospital stay, total perioperative complications, pain score, time to first flatus, anastomotic leakage, surgical site infection (SSI), blood loss, and intraabdominal abscess; (5) study design: randomized controlled trials (RCTs), prospective non-randomized trials and retrospective trials based on NOSE. Exclusion criteria were as follows: (1) traditional open surgery; (2) non-colorectal diseases; (3) transanal total mesorectal excision surgery; (4) lack of data, or inability to obtain original data from the author; (5) case reports, letters, reviews, conference abstracts, animal experiments, and expert opinions; (6) studies not written in English or Chinese were excluded.

\section{Data Extraction and Quality Assessment}

Two researchers independently extracted data from the studies. For each included study, the following information was extracted: first author, year of publication, country of origin, number of patients, characteristics of the patients [age, gender, body mass index [BMI], clinical TNM stage, diseases type, extent of resection, specimen extraction approach, location of diseases], study type, information on outcome (primary outcomes: 5year DFS, lymph node harvest, anastomotic leakage, intraabdominal abscess, and SSI; secondary outcomes: operation time, hospital stay, pain score, time to first flatus, total perioperative complications, blood loss, proximal margin, and distal margin). If there were any doubts or disagreements regarding outcomes, these studies were submitted to a third researcher for arbitration. For retrospective and prospective non-randomized studies, the Newcastle-Ottawa Scale (NOS) was used (18). The assessment of bias in the RCTs was based on the Cochrane Risk of Bias tool (19).

\section{Statistical Analysis}

Review Manager Version 5.3 software (Cochrane Collaboration, Oxford, UK) was used for statistical analysis. For continuous 


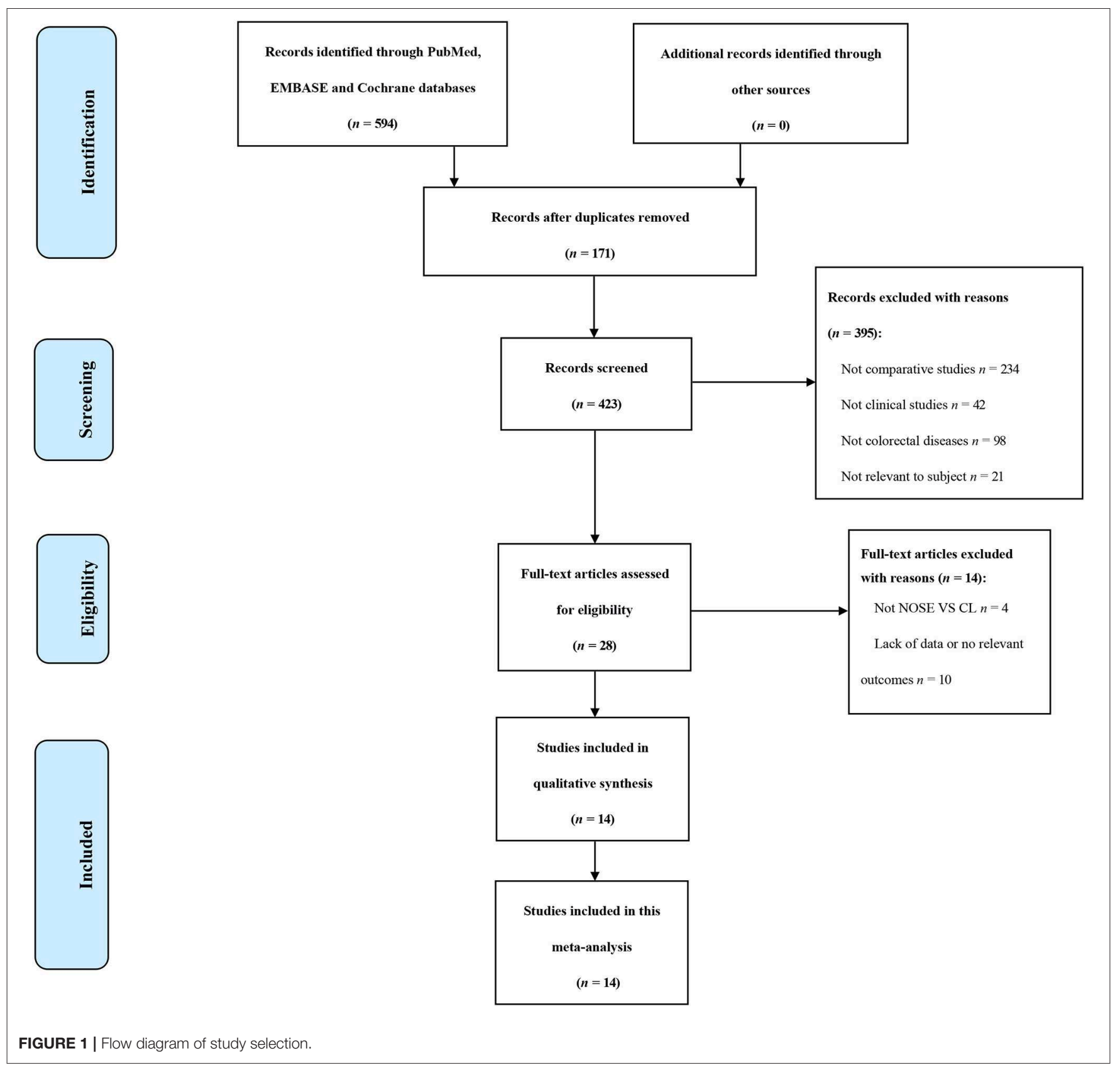

variables, weighted mean difference (WMD) was used. Odds ratio (OR) was used to express dichotomous variables. The hazard ratio (HR) of 5-year DFS was calculated from survival curves using the methods presented by Tierney et al. (20). The confidence interval (CI) was set at $95 \%$, and $P<0.05$ was considered statistically significant. The Chi-square test or Cochrane Q test was used to calculate heterogeneity, and $I^{2}<50 \%$ and $P>0.10$ were defined as non-significant heterogeneity, and such data were evaluated using the fixed effect model; otherwise, the random effect model was used $(21,22)$. Subgroup analyses were conducted according to the different study types [RCT and NRCT (non-randomized controlled trial)]. A sensitivity analysis was carried out to evaluate the stability of the outcomes. In addition, publication bias was assessed by Begg's funnel plots and Begg's test (STATA, version 12.0) (23).

\section{RESULTS}

\section{Study Selection and Characteristics}

A total of 14 studies were included in the meta-analysis [two RCTs $(12,24)$, seven retrospective studies $(4,5,10,11,25-$ $27)$, and five prospective non-randomized studies $(9,16,28-$ 30)]. A flow diagram of study selection is shown in Figure 1. 
TABLE 1 | Basic characteristics of the included studies.

\begin{tabular}{|c|c|c|c|c|c|c|c|c|c|c|c|c|c|c|c|}
\hline References & Year & $\begin{array}{c}\text { Country/ } \\
\text { area }\end{array}$ & $\begin{array}{l}\text { Patients } \\
\text { (NOSE/CL) }\end{array}$ & $\begin{array}{r}\text { Gend } \\
\text { (NOSE/ } \\
\text { (M/F }\end{array}$ & & $\mathrm{Age}^{\mathrm{a}}(\mathrm{NC}$ & OSE/CL) & $\mathrm{BM}^{\mathrm{a}}$ (N & OSE/CL) & $\begin{array}{l}\text { Study } \\
\text { type }\end{array}$ & Approach & $\begin{array}{l}\text { Disease } \\
\text { type }\end{array}$ & CTNM & $\begin{array}{l}\text { Extent of } \\
\text { resection } \\
\text { (NOSE/CL) }\end{array}$ & Location \\
\hline Hisada et al. (4) & 2014 & Japan & $20 / 50$ & $12 / 8$ & NA & $63.7 \pm 9.0$ & $66.3 \pm 11.0$ & NA & NA & RT & TS & Mal & $|-|||$ & NA & Rec \\
\hline Park et al. (5) & 2017 & Korea & $138 / 138$ & $32 / 106$ & $41 / 97$ & $60.3 \pm 10.6$ & $60.4 \pm 11.3$ & $23.4 \pm 2.9$ & $23.3 \pm 3.2$ & RT & $\mathrm{TS} / \mathrm{TV}$ & Mal & $0-111$ & NA & Rec \\
\hline $\begin{array}{l}\text { Costantino et al. } \\
\text { (9) }\end{array}$ & 2011 & France & $17 / 9$ & $6 / 11$ & $4 / 5$ & $60.1 \pm 9.4$ & $59.5 \pm 12.6$ & $25.5 \pm 3.0$ & $30.5 \pm 4.2$ & PNT & TS & Ben & NA & NA & SC \\
\hline Award et al. (10) & 2014 & USA & $20 / 20$ & $20(\mathrm{~F})$ & $20(F)$ & $63.6 \pm 9.0$ & $66.9 \pm 8.9$ & $25.1 \pm 6.7$ & $31.6 \pm 8.3$ & RT & TV & Ben/Mal & $|-|||$ & $\begin{array}{l}24.4 \pm 5.9 / \\
40.1 \pm 26.8\end{array}$ & $\mathrm{RC}$ \\
\hline Zhang et al. (11) & 2014 & China & $65 / 132$ & $32 / 33$ & $57 / 75$ & $56.1 \pm 9.3$ & $55.5 \pm 9.5$ & $23.7 \pm 2.9$ & $23.1 \pm 3.1$ & RT & TS & Mal & $|-|||$ & NA & SC, Rec \\
\hline Leung et al. (12) & 2013 & China & $35 / 35$ & $13 / 22$ & $12 / 23$ & $62(51-86)$ & $72(49-84)$ & NA & NA & RCT & TS & Mal & NA & NA & LC \\
\hline Park et al. (16) & 2011 & Korea & $34 / 34$ & $34(F)$ & $34(F)$ & $61.0 \pm 11.2$ & $63.6 \pm 11.6$ & $23.9 \pm 3.1$ & $23.1 \pm 2.7$ & PNT & TV & Mal & $|-|||$ & NA & $\mathrm{RC}$ \\
\hline Wolthuis et al. (24) & 2014 & Belgium & $20 / 20$ & $5 / 15$ & $10 / 10$ & $54(31-72)$ & $58(40-73)$ & 23.5 (18-29) & 24 (20-29) & $\mathrm{RCT}$ & TR & Ben/Mal & NA & $\begin{array}{l}25(12-44) / 18 \\
(12-33)\end{array}$ & SC \\
\hline Denost et al. (25) & 2015 & France & $122 / 98$ & $70 / 52$ & $69 / 29$ & 63 (20-90) & 65 (25-85) & $24.3(17.3-33.6)$ & $25.8(18.8-38.3)$ & RT & TS & Mal & $0-111$ & NA & Rec \\
\hline Saurabh et al. (26) & 2017 & Taiwan & $82 / 106$ & $47 / 35$ & $65 / 41$ & $63.3 \pm 13.9$ & $64.7 \pm 10.9$ & $24.4 \pm 4.2$ & $24.4 \pm 3.2$ & RT & TS & Ben/Mal & $|-|||$ & $\begin{array}{l}16 \pm 5.3 / \\
15.3 \pm 5.3\end{array}$ & SC, Rec \\
\hline Xu et al. (27) & 2016 & China & $23 / 23$ & $13 / 10$ & $13 / 10$ & $63.0 \pm 9.4$ & $63.5 \pm 13.5$ & $22.2 \pm 2.7$ & $22.2 \pm 3.3$ & RT & TS & Mal & $0-111$ & NA & $\mathrm{LC}, \operatorname{Rec}$ \\
\hline $\begin{array}{l}\text { Christoforidis et al. } \\
\text { (28) }\end{array}$ & 2012 & Switzerland & $10 / 20$ & $3 / 7$ & $10 / 10$ & 47 (26-62) & $56(38-81)$ & $27.6(19.7-30.9)$ & $26.4(19.4-31.6)$ & PNT & TR & Ben & NA & NA & LC, Rec \\
\hline Kim et al. (29) & 2014 & Korea & $58 / 58$ & $58(F)$ & $58(F)$ & $62.8 \pm 9.0$ & $63.2 \pm 10.7$ & $23.5 \pm 2.9$ & $23.2 \pm 3.3$ & PNT & TV & Mal & $|-|||$ & NA & LC \\
\hline Xing et al. (30) & 2017 & China & $16 / 32$ & $12 / 4$ & $24 / 8$ & $61.9 \pm 11.8$ & $62.4 \pm 12.0$ & $23.1 \pm 1.2$ & $23.9 \pm 1.7$ & PNT & TS & Mal & $|-||| \mid$ & $\begin{array}{l}18.2 \pm 4.8 / \\
19.8 \pm 5.7\end{array}$ & SC \\
\hline
\end{tabular}

NOSE, natural orifice specimen extraction; $C L$, conventional laparoscopic surgery; a, mean $\pm S D$ or median (range); SD, standard deviation; BMI, body mass index; NA, not available; RCT, randomized controlled trial; RT, retrospective trial; PNT, prospective non-randomized trial; cTNM, clinical TNM stage; M, male; F, female; Ben, benign; Mal, malignant; SC, sigmoid colon; LC, left colon; RC, right colon; Rec, rectum; TS, transanal; TV, transvaginal; TR, transrectal; ref, reference. 


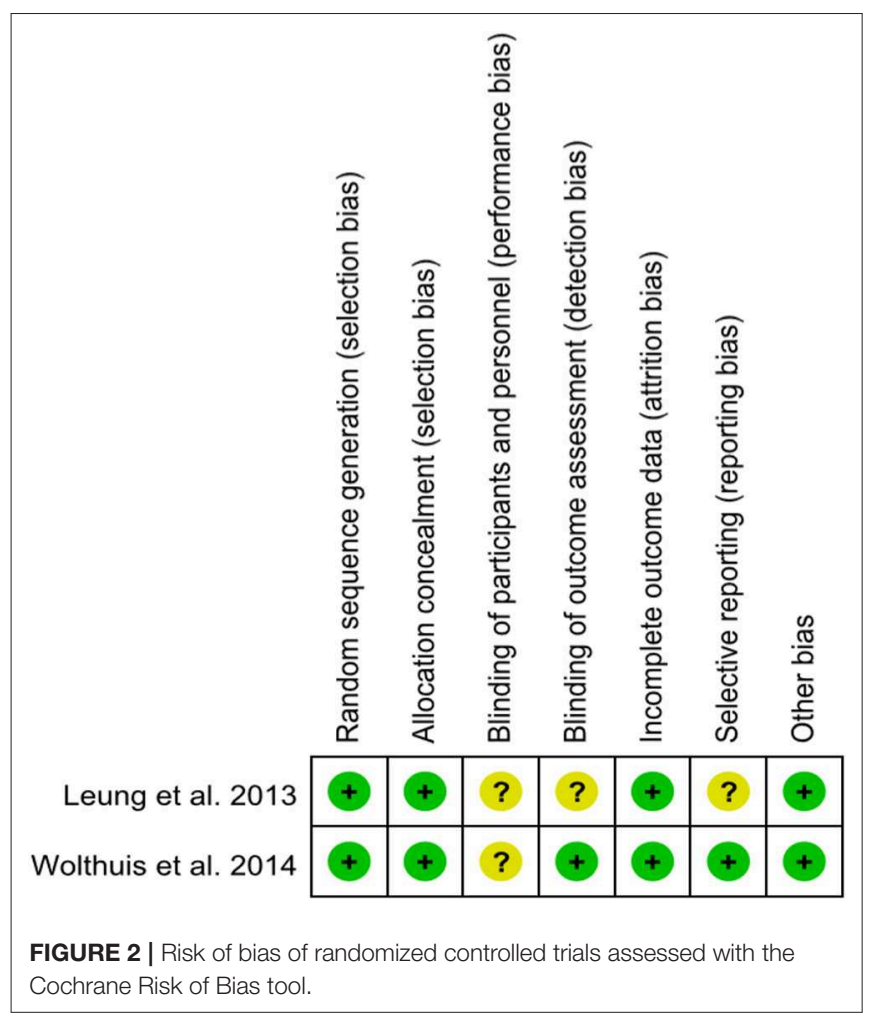

Nine studies were from Asia, four from Europe and one from North America. A total of 1,435 patients were included; 660 in the NOSE group and 775 in the CL surgery group. The two groups were similar in terms of age $(P=0.12)$, body mass index (BMI, $P=0.15)$, and extent of resection $(P=$ 0.86). In the included studies, the main steps of NOSE and CL regarding exploration, mobilization, and dissection were the same. NOSE involves a natural orifice for specimen extraction. However, CL surgery involves specimen extraction through the abdominal wall. The basic characteristics of the studies included are summarized in Table 1. All non-randomized studies had a NOS score of $\geq 5$, and RCTs had a low risk of bias. Quality assessment results of the included studies are shown in Table 2, Figure 2, respectively. Forest plots of all the outcomes are shown in Figures 3-5 and Supplementary Figures 1-10. The metaanalysis of the main endpoints is summarized in Table 3. The meta-analysis of endpoints for cancers is shown in Table 4, Supplementary Figures 1A, 4A-I.

\section{Oncological Outcomes}

Five-year DFS was reported in two studies $(5,25)$. Both of which were NRCTs. There was no significant difference in 5-year DFS between the NOSE and CL surgery groups ( $\mathrm{HR}=0.84 ; 95 \% \mathrm{CI}$ 0.54 to $1.31 ; P=0.45)$. No significant heterogeneity was observed $\left(I^{2}=0 \%\right)$; therefore, the fixed effect model was used (Figure 3, Supplementary Figure 1A).

A total of seven studies reported lymph node harvest $(4,10,11,16,26,29,30)$. All of which were NRCTs. There was no significant difference in lymph node harvest between the two groups (WMD $=-0.97 ; 95 \% \mathrm{CI}-1.97$ to $0.03 ; P=0.06)$. No significant heterogeneity was observed $\left(I^{2}=0 \%\right)$; therefore, the fixed effect model was used (Figure 3, Supplementary Figure 1B).

Data on proximal and distal margins were available in three studies $(26,27,29)$. All of which were NRCTs. There was no significant difference in proximal margin (WMD $=0.47 ; 95 \% \mathrm{CI}$ -0.49 to $1.42 ; P=0.34$ ) (Figure 3, Supplementary Figure 1C) and distal margin $(\mathrm{WMD}=-0.11 ; 95 \% \mathrm{CI}-0.66$ to $0.45 ; P$ $=0.70$ ) (Figure 3, Supplementary Figure 1D). No significant heterogeneity in proximal margin $\left(I^{2}=0 \%\right)$ and distal margin $\left(I^{2}=24 \%\right)$ was observed; therefore, the fixed effect model was used.

\section{Safety Outcomes}

A total of seven studies reported SSIs (4, 5, 10, 12, 26, 29, 30). There were fewer SSIs in the NOSE group, and the difference was significant $(\mathrm{OR}=0.15 ; 95 \% \mathrm{CI} 0.05$ to $0.42 ; P<0.001)$. No significant heterogeneity was observed $\left(I^{2}=0 \%\right)$; therefore, the fixed effect model was used. The pooled OR for the NRCT subgroup was 0.16 (95\% CI 0.05 to $0.48 ; P=0.001, I^{2}=0 \%$ ) (Figure 4, Supplementary Figure 2A).

Anastomotic leakage was reported in six studies (5, 9, $11,26,27,29)$. All of which were NRCTs. There was no significant difference in anastomotic leakage between the NOSE and $\mathrm{CL}$ surgery groups $(\mathrm{OR}=0.71 ; 95 \% \mathrm{CI} 0.36$ to 1.38 ; $P=0.31)$. No significant heterogeneity was observed $\left(I^{2}=\right.$ $0 \%$; therefore, the fixed effect model was used (Figure 4, Supplementary Figure 2B).

A total of seven studies reported blood loss $(4,5,11,16,26,27$, 30). All of which were NRCTs. There was no significant difference between the two groups (WMD $=-12.23$; 95\% CI -29.35 to 4.90; $P=0.16$ ). Heterogeneity was observed ( $P$ for heterogeneity $\left.<0.001, I^{2}=89 \%\right)$; therefore, the random effect model was used (Figure 4, Supplementary Figure 2C).

Data on intra-abdominal abscess were included in three studies $(5,16,29)$. All of which were NRCTs. There was no significant difference between the two groups (OR $=1.34$; 95\% CI $0.30-6.05 ; P=0.70)$. No significant heterogeneity was observed $\left(I^{2}=0 \%\right)$; therefore, the fixed effect model was used (Figure 4, Supplementary Figure 2D).

Data on total perioperative complications (such as wound infection, anastomotic leakage, ischemia, bleeding, ileus, and anal dysfunction) were reported in 12 studies (4, 5, 9-11, 16, 24-29). The results showed that the NOSE group had fewer complications than the CL surgery group (OR $=0.56$; $95 \% \mathrm{CI}$ 0.41 to $0.75 ; P<0.001)$. The difference was significant. No obvious heterogeneity was observed $\left(I^{2}=15 \%\right)$; therefore, the fixed effect model was used. The pooled OR for the NRCT subgroup was 0.55 (95\% CI $0.41-0.74 ; P<0.001, I^{2}=21 \%$ ) (Figure 4, Supplementary Figure 2E).

\section{Other Outcomes}

Data on operation time was available in 12 studies $(4,5,9-$ $12,16,26-30)$. Compared to the NOSE group, the operation time was shorter in the CL surgery group (WMD $=17.34 ; 95 \% \mathrm{CI}$ 6.14-28.54; $P=0.002$ ). Significant heterogeneity was observed 
TABLE 2 | Newcastle-Ottawa Scale for bias risk assessment of retrospective and prospective non-randomized studies.

\begin{tabular}{|c|c|c|c|c|c|c|c|c|c|}
\hline References & $\begin{array}{c}\text { Case } \\
\text { definition }\end{array}$ & Representativeness & $\begin{array}{l}\text { Control } \\
\text { selection }\end{array}$ & $\begin{array}{l}\text { Definition of } \\
\text { controls }\end{array}$ & Comparability & $\begin{array}{l}\text { Ascertainment } \\
\text { of exposure }\end{array}$ & SMACC & $\begin{array}{l}\text { Non- } \\
\text { response } \\
\text { rate }\end{array}$ & Total \\
\hline Hisada et al. (4) & 1 & 1 & 1 & 1 & 1 & 1 & 1 & 0 & 7 \\
\hline Park et al. (5) & 1 & 1 & 1 & 0 & 2 & 1 & 1 & 1 & 8 \\
\hline Costantino et al. (9) & 1 & 1 & 1 & 1 & 1 & 1 & 1 & 0 & 7 \\
\hline Award et al. (10) & 1 & 1 & 1 & 1 & 1 & 1 & 1 & 0 & 7 \\
\hline Zhang et al. (11) & 1 & 1 & 1 & 0 & 1 & 1 & 1 & 0 & 6 \\
\hline Park et al. (16) & 1 & 1 & 1 & 0 & 1 & 1 & 1 & 0 & 6 \\
\hline Denost et al. (25) & 1 & 1 & 1 & 0 & 2 & 1 & 1 & 1 & 8 \\
\hline Saurabh et al. (26) & 1 & 1 & 1 & 0 & 1 & 1 & 1 & 0 & 6 \\
\hline Xu et al. (27) & 1 & 0 & 1 & 0 & 1 & 1 & 1 & 0 & 5 \\
\hline Christoforidis et al. (28) & 1 & 1 & 1 & 1 & 1 & 1 & 1 & 0 & 7 \\
\hline Kim et al. (29) & 1 & 1 & 1 & 0 & 1 & 1 & 1 & 1 & 7 \\
\hline Xing et al. (30) & 1 & 0 & 1 & 0 & 1 & 1 & 1 & 0 & 5 \\
\hline
\end{tabular}

SMACC, same method of ascertainment for cases and controls.

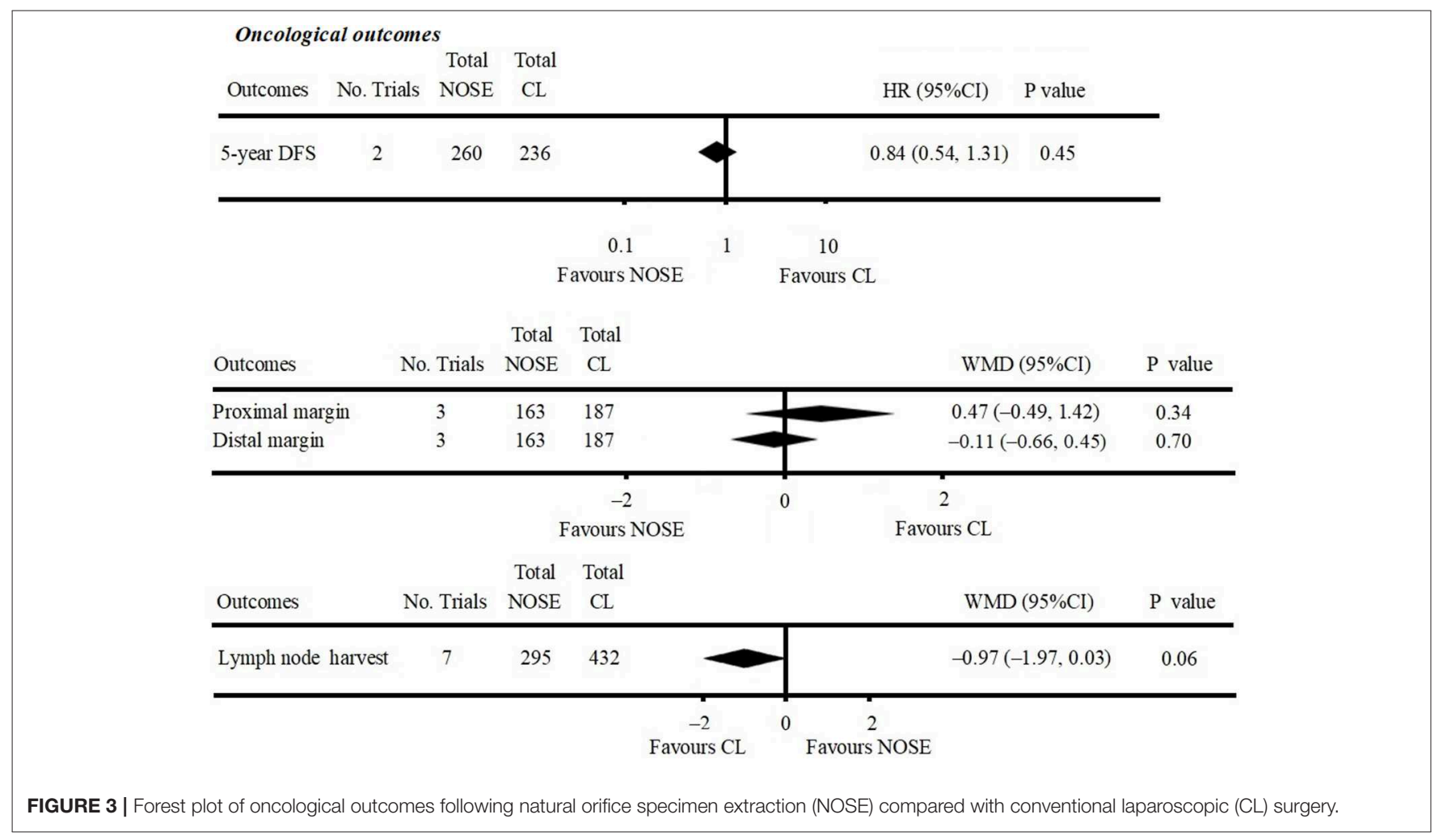

( $P$ for heterogeneity $<0.001, I^{2}=81 \%$ ); therefore, the random effect model was used. The pooled WMD for the NRCT subgroup was 18.83 (95\% CI 6.48-31.17; $P=0.003, I^{2}=82 \%$ ) (Figure 5, Supplementary Figure 3A).

A total of 12 studies reported data on hospital stay $(4,5,9-$ 12, 16, 26-30). Patients in the NOSE group had a reduced hospital stay compared with patients in the CL surgery group. The difference was significant (WMD $=-0.56$; 95\% CI -1.09 to $-0.04 ; P=0.03)$. Significant heterogeneity was observed $(P$ for heterogeneity $=0.01, I^{2}=54 \%$ ); therefore, the random effect model was used. The pooled WMD for the NRCT subgroup was -0.66 (95\% CI -1.22 to $-0.10 ; P=0.02, I^{2}=50 \%$ ) (Figure 5, Supplementary Figure 3B).

Five studies reported pain score using the visual analog scale (VAS) on post-operative day $1(9,11,16,29,30)$. All of which were NRCTs. The NOSE group had a lower VAS score than the CL surgery group. The difference was significant (WMD $=-1.42 ; 95 \% \mathrm{CI}-1.94$ to $-0.90 ; P<0.001)$. Significant 


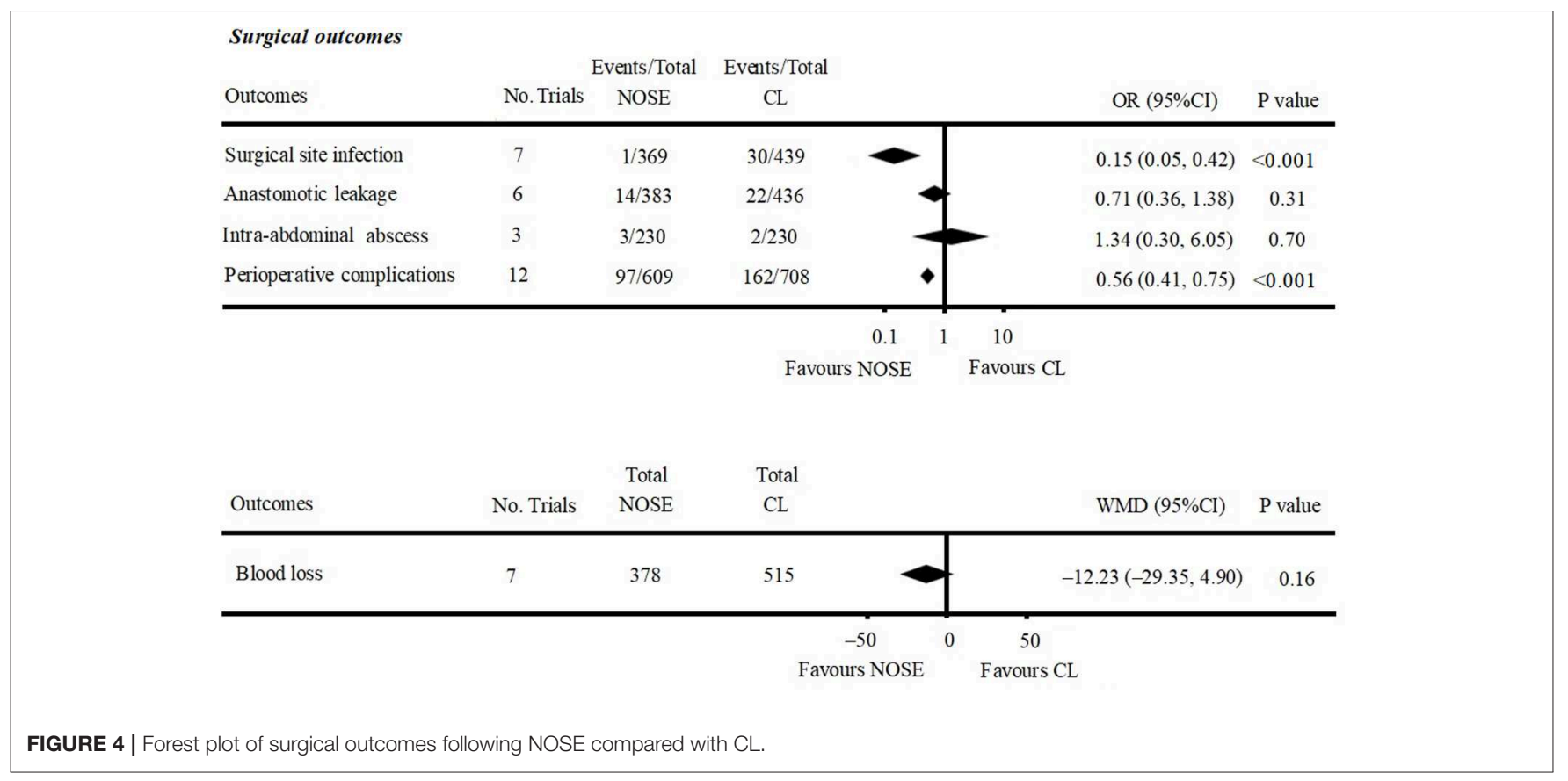

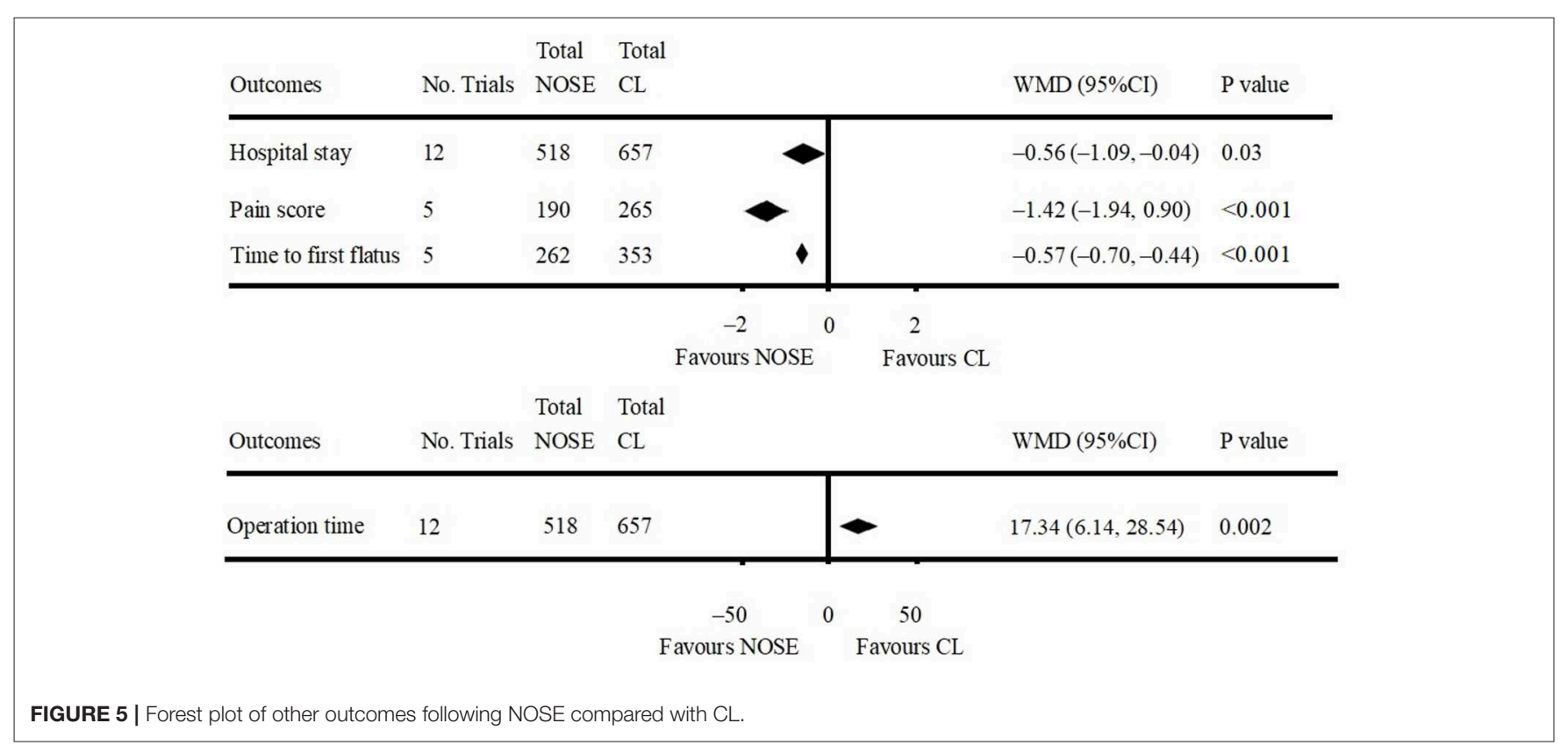

heterogeneity was observed ( $P$ for heterogeneity $<0.001, I^{2}=$ $85 \%$ ); therefore, the random effect model was used (Figure 5, Supplementary Figure 3C).

Data on time to first flatus was included in five studies (11, 16, 26, 27, 29). All of which were NRCTs. Compared with the CL surgery group, time to first flatus was shorter in the NOSE group. The difference was significant $(\mathrm{WMD}=-0.57 ; 95 \% \mathrm{CI}-0.70$ to $-0.44 ; P<0.001)$. No significant heterogeneity was observed $\left(I^{2}=0 \%\right)$; therefore, the fixed effect model was used (Figure 5, Supplementary Figure 3D).

\section{Publication Bias}

We performed a funnel plot of the studies included to assess publication bias. No obvious asymmetry was noted and none of the studies were outside the limits of the 95\% CI (Figure 6). No significant publication bias among these studies was observed using Begg's test $(P=0.373)$. In addition, a sensitivity analysis was performed using six outcomes (lymph node harvest, SSI, anastomotic leakage, total perioperative complications, operation time, hospital stay) and the results are shown in Table 5. Forest plots based on exclusion criteria in the sensitivity analysis are 
TABLE 3 | Meta-analysis of main endpoints.

\begin{tabular}{|c|c|c|c|c|c|c|c|c|}
\hline Endpoints & $\begin{array}{c}\text { No. of } \\
\text { patients }\end{array}$ & $\begin{array}{l}\text { No. of trials } \\
\text { (No. of RCTs) }\end{array}$ & NOSE & CL & $\begin{array}{l}\text { HR/OR/WMD } \\
(95 \% \mathrm{Cl})\end{array}$ & $P$-value & $I^{2}(\%)$ & $\begin{array}{l}P \text {-value for } \\
\text { heterogeneity }\end{array}$ \\
\hline \multicolumn{9}{|c|}{ ONCOLOGICAL OUTCOMES (REFERENCES) } \\
\hline Five-year DFS $(5,25)$ & 496 & $2(0)$ & 260 & 236 & $0.84(0.54$ to 1.31$)$ & 0.45 & 0 & 0.83 \\
\hline $\begin{array}{l}\text { Lymph node harvest } \\
(4,10,11,16,26,29,30)\end{array}$ & 727 & $7(0)$ & 295 & 432 & -0.97 ( -1.97 to 0.03$)$ & 0.06 & 0 & 0.76 \\
\hline $\begin{array}{l}\text { Proximal margin, cm } \\
(26,27,29)\end{array}$ & 350 & $3(0)$ & 163 & 187 & $0.47(-0.49$ to 1.42$)$ & 0.34 & 0 & 0.72 \\
\hline $\begin{array}{l}\text { Distal margin, cm } \\
(26,27,29)\end{array}$ & 350 & $3(0)$ & 163 & 187 & $-0.11(-0.66$ to 0.45$)$ & 0.70 & 24 & 0.27 \\
\hline \multicolumn{9}{|l|}{ SAFETY OUTCOMES } \\
\hline $\begin{array}{l}\text { Surgical site infection } \\
(4,5,10,12,26,29,30)\end{array}$ & 808 & $7(1)$ & 369 & 439 & 0.15 (0.05 to 0.42$)$ & $<0.001$ & 0 & 0.99 \\
\hline $\begin{array}{l}\text { Anastomotic leakage } \\
(5,9,11,26,27,29)\end{array}$ & 819 & $6(0)$ & 383 & 436 & 0.71 (0.36 to 1.38$)$ & 0.31 & 0 & 0.96 \\
\hline $\begin{array}{l}\text { Blood loss, } \mathrm{ml} \\
(4,5,11,16,26,27,30)\end{array}$ & 893 & $7(0)$ & 378 & 515 & $-12.23(-29.35$ to 4.90$)$ & 0.16 & 89 & $<0.001$ \\
\hline $\begin{array}{l}\text { Intra-abdominal abscess } \\
(5,16,29)\end{array}$ & 460 & $3(0)$ & 230 & 230 & 1.34 (0.30 to 6.05) & 0.70 & 0 & 0.47 \\
\hline $\begin{array}{l}\text { Total perioperative } \\
\text { complications } \\
(4,5,9-11,16,24-29)\end{array}$ & 1,317 & $12(1)$ & 609 & 708 & $0.56(0.41$ to 0.75$)$ & $<0.001$ & 15 & 0.30 \\
\hline \multicolumn{9}{|l|}{ OTHER OUTCOMES } \\
\hline $\begin{array}{l}\text { Operation time, } \min \\
(4,5,9-12,16,26-30)\end{array}$ & 1,175 & $12(1)$ & 518 & 657 & $17.34(6.14$ to 28.54$)$ & 0.002 & 81 & $<0.001$ \\
\hline $\begin{array}{l}\text { Hospital stay, day } \\
(4,5,9-12,16,26-30)\end{array}$ & 1,175 & $12(1)$ & 518 & 657 & $-0.56(-1.09$ to -0.04$)$ & 0.03 & 54 & 0.01 \\
\hline $\begin{array}{l}\text { Pain score } \\
(9,11,16,29,30)\end{array}$ & 455 & $5(0)$ & 190 & 265 & $-1.42(-1.94$ to 0.90$)$ & $<0.001$ & 85 & $<0.001$ \\
\hline $\begin{array}{l}\text { Time to first flatus, day } \\
(11,16,26,27,29)\end{array}$ & 615 & $5(0)$ & 262 & 353 & $-0.57(-0.70$ to -0.44$)$ & $<0.001$ & 0 & 0.48 \\
\hline
\end{tabular}

NOSE, natural orifice specimen extraction; CL, conventional laparoscopic surgery; HR, hazard ratio; OR, odds ratio; WMD, weighted mean difference; $95 \%$ Cl; $95 \%$ confidence interval; DFS, diseases-free survival.

shown in Supplementary Figures 5-10. Finally, exclusion of any single study and sensitivity analysis based on various exclusion criteria did not affect the pooled results, except hospital stay based on prospective studies.

\section{DISCUSSION}

This meta-analysis mainly focused on the oncological and safety outcomes of laparoscopic colorectal surgery using NOSE. We found that oncological outcomes and safety outcomes of NOSE were not significantly different to those of CL surgery.

Surgical safety is always an important concern for surgeons. Severe post-operative complications may even lead to failure of the entire operation (31-34). An enterotomy within the peritoneal cavity and insertion of an anvil into the abdominal cavity through a natural orifice are necessary in some approaches of NOSE, which can cause bacteriological concerns $(13,28,35)$. Costantino et al. and Wolthuis et al. studied the bacterial positive rate in peritoneal fluid culture and demonstrated that, although NOSE had a higher risk of peritoneal contamination, there were no significant differences in clinical outcomes between the two groups $(9,24)$. Recently, a multicenter study of 718 cases from China further showed that the incidence of intraperitoneal infection after NOSE was only $0.8 \%$ (36). To reduce the risk of peritoneal bacterial contamination, pre-operative administration of prophylactic antibiotics, pre-operative bowel preparation, intraoperative peritoneal irrigation and intraoperative transanal lavage are considered routine procedures in NOSE (15). From our pooled data, SSI was reduced in the NOSE group and the incidence of intra-abdominal abscess was not significantly different between the two groups. Post-operative anastomotic leakage is another severe complication in colorectal surgery, and must be avoided. Several factors are considered to increase the incidence of anastomotic leakage, such as excessive tension in the reconstructed bowel, anastomotic ischemia, and anastomotic technique (4, 33). A circular stapler device and end-to-end anastomosis are commonly used in both groups. However, anastomosis in CL colectomy is performed extracorporeally and differs from that in totally laparoscopic surgery with intracorporeal anastomosis (IA). During laparoscopic left colectomy with extracorporeal anastomosis (EA), exteriorization of the bowel requires greater mobilization of colonic segments and the mesentery, which may result in mesenteric laceration and bleeding, further endangering the blood supply of the anastomotic stoma. However, IA requires less mobilization than EA, and therefore facilitates the achievement of tension-free anastomosis. Recent studies have demonstrated that compared to 
TABLE 4 | Meta-analysis of endpoints for cancers.

\begin{tabular}{|c|c|c|c|c|c|c|c|c|}
\hline Endpoints (references) & $\begin{array}{c}\text { No. of } \\
\text { patients }\end{array}$ & $\begin{array}{l}\text { No. of trials } \\
\text { (No. of RCTs) }\end{array}$ & NOSE & CL & $\begin{array}{l}\text { HR/OR/WMD } \\
\text { (95\% Cl) }\end{array}$ & $P$-value & $I^{2}(\%)$ & $\begin{array}{l}P \text {-value for } \\
\text { heterogeneity }\end{array}$ \\
\hline Five-year DFS $(5,25)$ & 496 & $2(0)$ & 260 & 236 & 0.84 (0.54 to 1.31$)$ & 0.45 & 0 & 0.83 \\
\hline $\begin{array}{l}\text { Lymph node harvest } \\
(4,11,16,29,30)\end{array}$ & 499 & $5(0)$ & 193 & 306 & $-1.15(-2.40$ to 0.11$)$ & 0.07 & 0 & 0.75 \\
\hline Proximal margin, cm $(27,29)$ & 162 & $2(0)$ & 81 & 81 & $1.24(-1.03$ to 3.50$)$ & 0.28 & 0 & 0.74 \\
\hline Distal margin, cm $(27,29)$ & 162 & $2(0)$ & 81 & 81 & $-0.48(-1.21$ to 0.25$)$ & 0.20 & 0 & 0.59 \\
\hline $\begin{array}{l}\text { Surgical site infection } \\
(4,5,12,29,30)\end{array}$ & 580 & $5(1)$ & 267 & 313 & 0.14 (0.04 to 0.46$)$ & 0.001 & 0 & 0.98 \\
\hline $\begin{array}{l}\text { Anastomotic leakage } \\
(5,11,27,29)\end{array}$ & 605 & $4(0)$ & 284 & 321 & 0.65 (0.31 to 1.37$)$ & 0.25 & 0 & 0.88 \\
\hline $\begin{array}{l}\text { Blood loss, } \mathrm{ml} \\
(4,5,11,16,27,30)\end{array}$ & 705 & $6(0)$ & 296 & 409 & $-12.35(-32.62$ to 7.93$)$ & 0.23 & 91 & $<0.001$ \\
\hline $\begin{array}{l}\text { Total perioperative complications } \\
(4,5,11,16,26,27,29)\end{array}$ & 993 & $7(0)$ & 460 & 533 & 0.52 (0.37 to 0.73$)$ & $<0.001$ & 0 & 0.46 \\
\hline $\begin{array}{l}\text { Operation time, } \min \\
(4,5,11,12,16,27,29,30)\end{array}$ & 891 & $8(1)$ & 389 & 502 & 13.70 (0.97 to 26.43) & 0.03 & 83 & $<0.001$ \\
\hline $\begin{array}{l}\text { Hospital stay, day } \\
(4,5,11,12,16,27,29,30)\end{array}$ & 891 & $8(1)$ & 389 & 502 & $-0.64(-1.19$ to -0.09$)$ & 0.02 & 55 & 0.03 \\
\hline
\end{tabular}

NOSE, natural orifice specimen extraction; CL, conventional laparoscopic surgery; OR, odds ratio; WMD, weighted mean difference; 95\%Cl; 95\% confidence interval; Unite; min, minute.

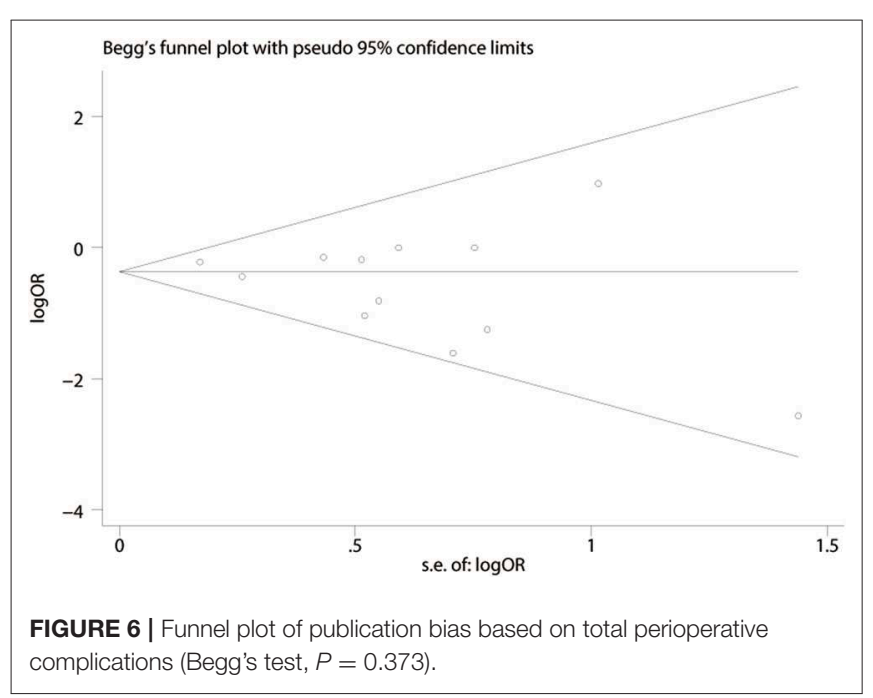

EA, IA is not associated with a greater incidence of anastomotic leakage (37-39). NOSE has a significant advantage in that it reduces anastomotic leakage in ultra-low rectal anus-preserving surgery (40). Unlike CL surgery in a narrow pelvic cavity, NOSE can evaginate the rectal specimen through the anus to the external, and easily close the distal rectum end under direct vision, further reducing the incidence of anastomotic leakage (41). The incidence of anastomotic leakage across the included studies in the NOSE group was 3.6\% and was $5 \%$ in the CL group (Figure 4). From the pooled data in the present study, the incidence of anastomotic leakage was not significantly different between the two groups. In summary, we consider that laparoscopic colorectal surgery with NOSE is surgically safe.

Lymph node metastasis, local recurrence (LR) and positive margin are life-threatening conditions in colorectal cancer surgery, often associated with worse overall survival (OS) and DFS (42-47). In this study, we used 5-year DFS to evaluate the long-term oncological safety of the NOSE technique. Anatomically, the distribution of lymphatic vessels is in parallel with the colonic mesenteric vessels. When the pre-resection margin of the bowel is determined, the corresponding mesenteric vessels are ligated, and the adherent lymph nodes are removed accordingly. The exploration, mobilization and dissection steps in NOSE and CL are almost the same, which indicates a similar lymph node harvest in both groups. In our meta-analysis, the number of lymph nodes harvested was not significantly different between the two groups. In addition, the 2017 National Comprehensive Cancer Network guidelines recommend removal of at least 12 lymph nodes during lymphadenectomy for cancer surgery. In all the studies included, more than 12 lymph nodes were removed in each group. Therefore, we suggest that laparoscopic NOSE can achieve adequate lymph node harvest similar to CL surgery. Complying with the principle of tumorfree during surgery is another challenge for NOSE. This concern arises from an incision at the colorectal stump (or vagina) in the abdominopelvic cavity and specimen extraction through a narrow natural orifice which may cause cancer cell implantation, and is a significant issue regarding LR and DFS (48). However, in clinical practice, the following steps are taken to reduce the risk of tumor seeding and peritoneal contamination: distal cytocidal rectal lavage; and a specimen extraction bag or a professional platform [transanal endoscopic operation [TEO] device or transanal endoscopic microsurgery [TEM] device] is inserted during the retrieval phase (15). Moreover, previous studies have confirmed that LR after NOSE is comparable to CL $(5,25)$. A tumor can achieve distant invasion by intramural spread; therefore, inadequate surgical resection may lead to a positive margin which is an independent factor of DFS (49). Three of the included studies reported surgical margin status 
TABLE 5 | Sensitivity analysis of endpoints of interests.

\begin{tabular}{|c|c|c|c|c|c|c|c|c|}
\hline Endpoints (references) & No. of patients & No. of trials & NOSE & CL & OR or WMD $(95 \% \mathrm{Cl})$ & $P$-value & $I^{2}(\%)$ & $\begin{array}{c}P \text { value for } \\
\text { heterogeneity }\end{array}$ \\
\hline \multicolumn{9}{|l|}{ LYMPH NODE HARVEST } \\
\hline All included trails $(4,10,11,16,26,29,30)$ & 727 & 7 & 295 & 432 & $-0.97(-1.97$ to 0.03$)$ & 0.06 & 0 & 0.76 \\
\hline $\mathrm{BMI} \leq 30\left(\mathrm{~kg} / \mathrm{m}^{2}\right)(4,11,16,26,29,30)$ & 687 & 6 & 275 & 412 & $-0.87(-1.89$ to 0.16$)$ & 0.10 & 0 & 0.77 \\
\hline Sample number > $30(11,16,26,29)$ & 569 & 4 & 239 & 330 & $-0.59(-1.99$ to 0.80$)$ & 0.41 & 0 & 0.64 \\
\hline Non-RCT (NOS $\geq 6)(4,10,11,16,26,29)$ & 679 & 6 & 279 & 400 & $-0.71(-1.98$ to 0.56$)$ & 0.27 & 0 & 0.71 \\
\hline Prospective trials $(16,29,30)$ & 232 & 3 & 108 & 124 & $-1.11(-2.59$ to 0.38$)$ & 0.14 & 0 & 0.53 \\
\hline \multicolumn{9}{|l|}{ TOTAL PERIOPERATIVE COMPLICATIONS } \\
\hline All included trails $(4,5,9-11,16,24-29)$ & 1,317 & 12 & 609 & 708 & 0.56 (0.41 to 0.75$)$ & $<0.001$ & 15 & 0.30 \\
\hline $\mathrm{BMI} \leq 30\left(\mathrm{~kg} / \mathrm{m}^{2}\right)(4,5,11,16,24,26,27,29)$ & 1,001 & 8 & 440 & 561 & $0.50(0.34$ to 0.74$)$ & $<0.001$ & 0 & 0.52 \\
\hline Sample number > $30(5,11,16,25,26,29)$ & 1,065 & 6 & 499 & 566 & 0.57 (0.41 to 0.79$)$ & $<0.001$ & 0 & 0.59 \\
\hline $\begin{array}{l}\text { Non-RCT }(\mathrm{NOS} \geq 6) \\
(4,5,9-11,16,25,26,28,29)\end{array}$ & 1,231 & 10 & 566 & 665 & 0.57 (0.42 to 0.78$)$ & $<0.001$ & 11 & 0.34 \\
\hline Prospective trials $(5,9,16,24,29)$ & 526 & 5 & 267 & 259 & 0.58 (0.36 to 0.93$)$ & 0.03 & 0 & 0.41 \\
\hline \multicolumn{9}{|l|}{ ANASTOMOTIC LEAKAGE } \\
\hline All included trails $(5,9,11,26,27,29)$ & 819 & 6 & 383 & 436 & 0.71 (0.36 to 1.38$)$ & 0.31 & 0 & 0.96 \\
\hline $\mathrm{BMI} \leq 30\left(\mathrm{~kg} / \mathrm{m}^{2}\right)(5,11,26,27,29)$ & 793 & 5 & 366 & 427 & 0.68 (0.34 to 1.34$)$ & 0.26 & 0 & 0.95 \\
\hline Sample number > $30(5,11,26,29)$ & 747 & 4 & 343 & 404 & $0.70(0.35$ to 1.42$)$ & 0.33 & 0 & 0.92 \\
\hline Non-RCT (NOS $\geq 6$ ) $(5,9,11,26,29)$ & 773 & 5 & 360 & 413 & 0.73 (0.37 to 1.46$)$ & 0.38 & 0 & 0.94 \\
\hline Prospective trials $(5,29)$ & 392 & 2 & 196 & 196 & 0.75 (0.31 to 1.78$)$ & 0.51 & 0 & 0.60 \\
\hline \multicolumn{9}{|l|}{ SURGICAL SITE INFECTION } \\
\hline All included trails $(4,5,10,12,26,29,30)$ & 808 & 7 & 369 & 439 & 0.15 (0.05 to 0.42$)$ & $<0.001$ & 0 & 0.99 \\
\hline $\mathrm{BMl} \leq 30\left(\mathrm{~kg} / \mathrm{m}^{2}\right)(4,5,12,26,29,30)$ & 768 & 6 & 349 & 419 & 0.14 (0.04 to 0.42$)$ & $<0.001$ & 0 & 0.99 \\
\hline Sample number > $30(5,12,26,29)$ & 650 & 4 & 313 & 337 & 0.12 (0.03 to 0.45$)$ & 0.002 & 0 & 1.00 \\
\hline Non-RCT (NOS $\geq 6)(4,5,10,26,29)$ & 690 & 5 & 318 & 372 & $0.14(0.04$ to 0.47$)$ & 0.001 & 0 & 0.99 \\
\hline Prospective trials $(5,12,29,30)$ & 510 & 4 & 247 & 263 & $0.14(0.04$ to 0.53$)$ & 0.004 & 0 & 0.93 \\
\hline \multicolumn{9}{|l|}{ OPERATION TIME } \\
\hline All included trails $(4,5,9-12,16,26-30)$ & 1,175 & 12 & 518 & 657 & $17.34(6.14$ to 28.54$)$ & 0.002 & 81 & $<0.001$ \\
\hline $\begin{array}{l}\mathrm{BMI} \leq 30\left(\mathrm{~kg} / \mathrm{m}^{2}\right) \\
(4,5,11,12,16,26,27,29,30)\end{array}$ & 1,079 & 9 & 471 & 608 & $13.17(1.86$ to 24.47$)$ & 0.02 & 80 & $<0.001$ \\
\hline Sample number > $30(5,11,12,16,26,29)$ & 915 & 6 & 412 & 503 & 11.08 (0.46 to 21.70$)$ & 0.04 & 72 & 0.003 \\
\hline Non-RCT (NOS $\geq 6$ ) $(4,5,9-11,16,26,28,29)$ & 1,011 & 9 & 444 & 567 & 14.84 (1.04 to 28.63$)$ & 0.03 & 81 & $<0.001$ \\
\hline Prospective trials $(5,9,12,16,29,30)$ & 604 & 6 & 298 & 306 & 17.36 (11.43 to 23.28$)$ & $<0.001$ & 0 & 0.65 \\
\hline \multicolumn{9}{|l|}{ HOSPITAL STAY } \\
\hline All included trails $(4,5,9-12,16,26-30)$ & 1,175 & 12 & 518 & 657 & $-0.56(-1.09$ to -0.04$)$ & 0.03 & 54 & 0.01 \\
\hline $\begin{array}{l}\mathrm{BMI} \leq 30\left(\mathrm{~kg} / \mathrm{m}^{2}\right) \\
(4,5,11,12,16,26,27,29,30)\end{array}$ & 1,079 & 9 & 471 & 608 & $-0.71(-1.19$ to -0.23$)$ & 0.004 & 51 & 0.04 \\
\hline Sample number > $30(5,11,12,16,26,29)$ & 915 & 6 & 412 & 503 & $-0.84(-1.16$ to -0.53$)$ & $<0.001$ & 43 & 0.12 \\
\hline Non-RCT (NOS $\geq 6)(4,5,9-11,16,26,28,29)$ & 1,011 & 9 & 444 & 567 & $-0.88(-1.21$ to -0.56$)$ & $<0.001$ & 41 & 0.09 \\
\hline Prospective trials $(5,9,12,16,29,30)$ & 604 & 6 & 298 & 306 & $-0.57(-1.35$ to 0.20$)$ & 0.15 & 62 & 0.02 \\
\hline
\end{tabular}

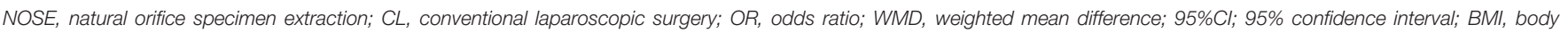
mass index.

$(26,27,29)$. All of which showed no positive surgical margin in the NOSE procedures, and the margin was the recommended distance from the center of the tumor (50). From our pooled data, the proximal margin and distal margin in the NOSE group were not significantly different compared to the CL group. We also conclude from this meta-analysis that 5-year DFS in the two treatment groups was not significantly different. Based on the above findings, we suggest that laparoscopic colorectal surgery with NOSE meets the expectations concerning oncological safety.
Previous studies have reported faster gastrointestinal recovery, less post-operative pain and shorter hospital stay following laparoscopic colorectal surgery with NOSE (51-54). The results of our meta-analysis also suggested that the NOSE group had less post-operative pain, shorter hospital stay and shorter time to first flatus. Possible reasons for these advantages are as follows: Laparotomy incision which traumatizes the abdominal wall, is more likely to cause vessel and nerve injury, and lead to increasing post-operative somatic pain (16). Reduction of pain is constructive for post-operative stress which consists 
of inflammatory cascades, which once activated, may have an adverse influence on recovery and hospital stay (55). Several studies have also reported a decrease in post-operative analgesia requirement, which may be beneficial for faster recovery $(24,26$, 29). The NOSE technique is conducted totally intraperitoneal; therefore, avoids intraabdominal organs contacting the external environment, and disturbance in the abdominal cavity is slight (56). In addition, patients in the NOSE group had early ambulation which also led to faster gastrointestinal recovery $(11,57)$. However, the operation time in the CL surgery group was shorter than that in the NOSE group, probably due to the time needed for purse-string suturing and anastomosis of the colorectal stump $(10,16)$. One study reported a decreasing trend in operation time, indicating the existence of a learning curve in NOSE (4). Therefore, we are convinced that an experienced surgeon may not need more time to complete this procedure. In conclusion, as an incisionless operation, the NOSE technique can aid early post-operative recovery of gastrointestinal function.

However, there were some limitations in our meta-analysis. Firstly, only two RCTs were included in our study, which may influence the power of pooled results. Secondly, differences in surgical proficiency in NOSE technology, $\mathrm{T}$ stage and tumor location may lead to heterogeneity of some results. For instance, operation time ranged from $\sim 105-240 \mathrm{~min}$ and hospital stay from about 4.8-12.9 $\mathrm{d}$ in the NOSE group. Thirdly, long-term outcomes such as LR and OS are still lacking which could provide further support of oncological safety.

Ma et al. conducted a meta-analysis on NOSE in 2015 (58). The analysis included nine studies and a total of 837 patients, and concluded that laparoscopic colorectal surgery with NOSE can reduce the duration of hospital stay, accelerate post-operative recovery with better cosmetic results, and result in less postoperative pain. However, there are still concerns regarding the surgical and oncological safety of this technique. Therefore, we conducted a meta-analysis of 14 studies including a total of 1,435 patients. Moreover, we analyzed studies only involving malignancies and concluded that the results were consistent with our conclusions. The results of the sensitivity analysis and subgroup analyses also support our conclusions and further provide robust evidence on the reliability of our results. All statistical methods mentioned above add credibility to the pooled results of our meta-analysis. In summary, 5-year DFS, lymph node harvest and surgical margin in the NOSE group were

\section{REFERENCES}

1. Braga M, Frasson M, Zuliani W, Vignali A, Pecorelli N, Di Carlo V. Randomized clinical trial of laparoscopic vs. open left colonic resection. $\mathrm{Br}$ J Surg. (2010) 97:1180-6. doi: 10.1002/bjs.7094

2. Lacy AM, García-Valdecasas JC, Delgado S, Castells A, Taurá P, Piqué JM, et al. Laparoscopy-assisted colectomy vs. open colectomy for treatment of non-metastatic colon cancer: a randomised trial. Lancet. (2002) 359:22249. doi: 10.1016/S0140-6736(02)09290-5

3. Wang CL, Qu G, Xu HW. The short- and long-term outcomes of laparoscopic vs. open surgery for colorectal cancer: a meta-analysis. Int J Colorectal Dis. (2014) 29:309-20. doi: 10.1007/s00384-013-1827-1 comparable to those in the CL group. Moreover, the NOSE group had similar blood loss and anastomotic leakage to the CL group, and a reduced incidence of SSI and total perioperative complications than the CL group.

In conclusion, laparoscopic colorectal surgery with NOSE can achieve comparable oncological and surgical safety to CL surgery. In addition, the NOSE technique has clear advantages in terms of early recovery of gastrointestinal function. However, large multicenter RCTs are needed in the future to provide high-level, evidence-based results regarding functional outcomes assessing anal or vaginal dysfunction and long-term oncological outcomes to further evaluate the feasibility of the NOSE technique.

\section{DATA AVAILABILITY}

Publicly available datasets were analyzed in this study. These data can be found at the following address: doi. http://doi.org/10.6084/m9.figshare.7856828.

\section{AUTHOR CONTRIBUTIONS}

R-JL and C-DZ contributed to study design, data extraction, data analysis, and manuscript writing. They also reviewed and revised the paper and approved and submitted the final manuscript. YCF reviewed and revised the paper. D-QD wrote, reviewed, and revised the paper and submitted the final manuscript. All authors approved the final manuscript and its submission.

\section{FUNDING}

C-DZ was supported in part by Japan China Sasakawa Medical Fellowship.

\section{ACKNOWLEDGMENTS}

We thank all the authors of previous studies and study participants for their support in this study.

\section{SUPPLEMENTARY MATERIAL}

The Supplementary Material for this article can be found online at: https://www.frontiersin.org/articles/10.3389/fonc. 2019.00597/full\#supplementary-material 
7. Singh R, Omiccioli A, Hegge S, McKinley C. Does the extraction-site location in laparoscopic colorectal surgery have an impact on incisional hernia rates? Surg Endosc. (2008) 22:2596-600. doi: 10.1007/s00464-008-9845-8

8. Winslow ER, Fleshman JW, Birnbaum EH, Brunt LM. Wound complications of laparoscopic vs. open colectomy. Surg Endosc. (2002) 16:1420-5. doi: 10.1007/s00464-002-8837-3

9. Costantino FA, Diana M, Wall J, Leroy J, Mutter D, Marescaux J. Prospective evaluation of peritoneal fluid contamination following transabdominal vs. transanal specimen extraction in laparoscopic left-sided colorectal resections. Surg Endosc. (2012) 26:1495-500. doi: 10.1007/s00464-011-2066-6

10. Awad ZT, Griffin R. Laparoscopic right hemicolectomy: a comparison of natural orifice vs. transabdominal specimen extraction. Surg Endosc. (2014) 28:2871-6. doi: 10.1007/s00464-014-3540-8

11. Xingmao Z, Haitao Z, Jianwei L, Huirong H, Junjie H, Zhixiang Z. Totally laparoscopic resection with natural orifice specimen extraction (NOSE) has more advantages comparing with laparoscopic-assisted resection for selected patients with sigmoid colon or rectal cancer. Int J Colorectal Dis. (2014) 29:1119-24. doi: 10.1007/s00384-014-1950-7

12. Leung AL, Cheung HY, Fok BK, Chung CC, Li MK, Tang CN. Prospective randomized trial of hybrid NOTES colectomy vs. conventional laparoscopic colectomy for left-sided colonic tumors. World J Surg. (2013) 37:267882. doi: $10.1007 / \mathrm{s} 00268-013-2163-\mathrm{x}$

13. Wolthuis AM, de Buck van Overstraeten A, D'Hoore A. Laparoscopic natural orifice specimen extraction-colectomy: a systematic review. World J Gastroenterol. (2014) 20:12981-92. doi: 10.3748/wig.v20.i36.12981

14. Chen C, Chen H, Yang M, Wu X, Yuan X, Zhu C, et al. Laparoscopy-assisted natural orifice specimen extraction to treat tumors of the sigmoid colon and rectum: the short- and long-term outcomes of a retrospective study. $J$ Laparoendosc Adv Surg Tech A. (2019) 29:801-8. doi: 10.1089/lap.2018.0601

15. Guan X, Liu Z, Longo A, Cai JC, Chen LC, International Alliance of NOSES. International consensus on natural orifice specimen extraction surgery (NOSES) for colorectal cancer. Gastroenterol Rep. (2019) 7:2431. doi: 10.1093/gastro/goy055

16. Park JS, Choi GS, Kim HJ, Park SY, Jun SH. Natural orifice specimen extraction vs. conventional laparoscopically assisted right hemicolectomy. Br J Surg. (2011) 98:710-5. doi: 10.1002/bjs.7419

17. Moher D, Liberati A, Tetzlaff J, Altman DG, Prisma Group. Preferred reporting items for systematic reviews and metaanalyses: the PRISMA statement. J Clin Epidemiol. (2009) 62:1006-12. doi: 10.1016/j.jclinepi.2009.06.005

18. Stang A. Critical evaluation of the Newcastle-Ottawa scale for the assessment of the quality of nonrandomized studies in meta-analyses. Eur J Epidemiol. (2010) 25:603-5. doi: 10.1007/s10654-010-9491-z

19. Higgins JP, Altman DG, Gøtzsche PC, Jüni P, Moher D, Oxman AD, et al. The Cochrane Collaboration's tool for assessing risk of bias in randomised trials. BMJ. (2011) 343:d5928. doi: 10.1136/bmj.d5928

20. Tierney JF, Stewart LA, Ghersi D, Burdett S, Sydes MR. Practical methods for incorporating summary time-to-event data into meta-analysis. Trials. 8:16. doi: 10.1186/1745-6215-8-16

21. Higgins JP, Thompson SG, Deeks JJ, Altman DG. Measuring inconsistency in meta-analyses. BMJ. (2003) 327:557-60. doi: 10.1136/bmj.327.7414.557

22. Petitti DB. Approaches to heterogeneity in meta-analysis. Stat Med. (2001) 20:3625-33. doi: 10.1002/sim.1091

23. Begg CB, Mazumdar M. Operating characteristics of a rank correlation test for publication bias. Biometrics. (1994) 50:1088-101. doi: 10.2307/2533446

24. Wolthuis AM, Fieuws S, Van Den Bosch A, de Buck van Overstraeten A, D'Hoore A. Randomized clinical trial of laparoscopic colectomy with or without natural-orifice specimen extraction. Br J Surg. (2014) 102:6307. doi: 10.1002/bjs. 9757

25. Denost Q, Adam JP, Pontallier A, Celerier B, Laurent C, Rullier E. Laparoscopic total mesorectal excision with coloanal anastomosis for rectal cancer. Ann Surg. (2015) 261:138-43. doi: 10.1097/SLA.0000000000000855

26. Saurabh B, Chang SC, Ke TW, Huang YC, Kato T, Wang HM, et al. Natural orifice specimen extraction with single stapling colorectal anastomosis for laparoscopic anterior resection: feasibility, outcomes, and technical considerations. Dis Colon Rectum. (2017) 60:43-50. doi: 10.1097/DCR.0000000000000739

27. Xu SZ, Ding ZJ, Zhang SF, Qiu XF, Yan F, Yuan SS, et al. Propensity score matching-based analysis of short-term outcomes of Laparoscopic-assisted Natural Orifice Specimen Extraction for left colorectal cancer radical resection. Zhonghua Yi Xue Za Zhi. (2016) 96:1578-81. doi: 10.3760/cma.j.issn.0376-2491.2016.20.007

28. Christoforidis D, Clerc D, Demartines N. Transrectal specimen extraction after laparoscopic left colectomy: a case-matched study. Colorectal Dis. (2012) 15:347-53. doi: 10.1111/codi.12006

29. Kim HJ, Choi GS, Park JS, Park SY, Ryuk JP, Yoon SH. Transvaginal specimen extraction vs. conventional minilaparotomy after laparoscopic anterior resection for colorectal cancer: mid-term results of a case-matched study. Surg Endosc. (2014) 28:2342-8. doi: 10.1007/s00464-014-3466-1

30. Xing J, Zhang C, Yang X, Wang H, Wang H, Yu E, et al. [Comparison of short-term outcomes of transrectal specimen extraction during laparoscopic sigmoid radical resection vs. conventional laparoscopically assisted procedure]. Zhonghua Wei Chang Wai Ke Za Zhi. (2017) 20:665-70. doi: 10.3760/cma.j.issn.1671-0274.2017.06.015

31. Frye J, Bokey EL, Chapuis PH, Sinclair G, Dent OF. Anastomotic leakage after resection of colorectal cancer generates prodigious use of hospital resources. Colorectal Dis. (2009) 11:917-20. doi: 10.1111/j.1463-1318.2008.01728.x

32. Boccola MA, Lin J, Rozen WM, Ho YH. Reducing anastomotic leakage in oncologic colorectal surgery: an evidence-based review. Anticancer Res. (2010) 30:601-7.

33. Frasson M, Granero-Castro P, Ramos Rodriguez JL, Flor-Lorente B, Braithwaite M, Marti Martinez E, et al. Risk factors for anastomotic leak and postoperative morbidity and mortality after elective right colectomy for cancer: results from a prospective, multicentric study of 1102 patients. Int $J$ Colorectal Dis. (2016) 31:105-14. doi: 10.1007/s00384-015-2376-6

34. Nikolian VC, Kamdar NS, Regenbogen SE, Morris AM, Byrn JC, Suwanabol $\mathrm{PA}$, et al. Anastomotic leak after colorectal resection: a population-based study of risk factors and hospital variation. Surgery. (2017) 161:161927. doi: 10.1016/j.surg.2016.12.033

35. Bucher P, Wutrich P, Pugin F, Gonzales M, Gervaz P, Morel P. Totally intracorporeal laparoscopic colorectal anastomosis using circular stapler. Surg Endosc. (2008) 22:1278-82. doi: 10.1007/s00464-007-9607-Z

36. Guan X, Wang GY, Zhou ZQ, Zhou HT, Chen YG. Retrospective study of 718 colorectal neoplasms treated by natural orifice specimen extraction surgery in 79 hospitals. Chin J Colorec Dis. (2017) 6:469-77. doi: 10.3877/cma.j.issn.2095-3224.2017.06.006

37. Carlini M, Spoletini D, Castaldi F, Giovannini C, Passaro U. Laparoscopic resection of splenic flexure tumors. Updates Surg. (2016) 68:77-83. doi: 10.1007/s13304-016-0357-0

38. Milone M, Angelini P, Berardi G, Burati M, Corcione F, Delrio P. Intracorporeal vs. extracorporeal anastomosis after laparoscopic left colectomy for splenic flexure cancer: results from a multiinstitutional audit on 181 consecutive patients. Surg Endosc. (2018) 32:3467-73. doi: 10.1007/s00464-018-6065-8

39. Swaid F, Sroka G, Madi H, Shteinberg D, Somri M, Matter I. Totally laparoscopic vs. laparoscopic-assisted left colectomy for cancer: a retrospective review. Surg Endosc. (2016) 30:24818. doi: $10.1007 / \mathrm{s} 00464-015-4502-5$

40. Wang X. [Prospects and challenges of natural orifice specimen extraction surgery, natural orifice transluminal endoscopic surgery and transanal total mesorectal excision]. Zhonghua Wei Chang Wai Ke Za Zhi. (2018) 21:856-61. doi: 10.3760/cma.j.issn.1671-0274.2018.08.003

41. Han FH, Hua LX, Zhao Z, Wu JH, Zhan WH. Transanal natural orifice specimen extraction for laparoscopic anterior resection in rectal cancer. World J Gastroenterol. (2013) 19:7751-7. doi: 10.3748/wjg.v19.i43.7751

42. Ishihara S, Nishikawa T, Tanaka T, Tanaka J, Kiyomatsu T, Kawai K, et al. Prognostic impact of tumor location in stage IV colon cancer: a propensity score analysis in a multicenter study. Int J Surg. (2014) 12:92530. doi: 10.1016/j.ijsu.2014.07.270

43. Iversen $\mathrm{H}$, Martling A, Johansson $\mathrm{H}$, Nilsson PJ, Holm T. Pelvic local recurrence from colorectal cancer: surgical challenge with changing preconditions. Colorectal Dis. (2018) 20:399-406. doi: 10.1111/codi.13966

44. Le Voyer TE, Sigurdson ER, Hanlon AL, Mayer RJ, Macdonald JS, Catalano $\mathrm{PJ}$, et al. Colon cancer survival is associated with increasing number of lymph nodes analyzed: a secondary survey of intergroup trial INT-0089. J Clin Oncol. (2003) 21:2912-9. doi: 10.1200/JCO.2003.05.062

45. Storli KE, Sondenaa K, Bukholm IR, Nesvik I, Bru T, Furnes B, et al. Overall survival after resection for colon cancer in a national cohort study was adversely affected by TNM stage, lymph node ratio, gender, and old age. Int $J$ Colorectal Dis. (2011) 26:1299-307. doi: 10.1007/s00384-011-1244-2 
46. Sudo M, Furuya S, Shimizu H, Nakata Y, Iino H, Shiraishi K, et al. Long-term outcomes after surgical resection in patients with stage IV colorectal cancer: a retrospective study of 129 patients at a single institution. World J Surg Oncol. (2019) 17:56. doi: 10.1186/s12957-019-1599-3

47. Swanson RS, Compton CC, Stewart AK, Bland KI. The prognosis of T3N0 colon cancer Is dependent on the number of lymph nodes examined. Ann Surg Oncol. (2003) 10:65-71. doi: 10.1245/ASO.2003. 03.058

48. Ngu J, Wong AS. Transanal natural orifice specimen extraction in colorectal surgery: bacteriological and oncological concerns. ANZ J Surg. (2016) 86:299302. doi: 10.1111/ans.13383

49. Birbeck KF, Macklin CP, Tiffin NJ Parsons W, Dixon MF, Mapstone NP, Abbott $\mathrm{CR}$, et al. Rates of circumferential resection margin involvement vary between surgeons and predict outcomes in rectal cancer surgery. Ann Surg. (2002) 235:449-57. doi: 10.1097/00000658-200204000-00001

50. Morlote DM, Alexis JB. Is the routine microscopic examination of proximal and distal resection margins in colorectal cancer surgery justified? Ann Diagn Pathol. (2016) 23:35-7. doi: 10.1016/j.anndiagpath.2016. 05.001

51. Flora ED, Wilson TG, Martin IJ, O’Rourke NA, Maddern GJ. A review of natural orifice translumenal endoscopic surgery (NOTES) for intra-abdominal surgery: experimental models, techniques, and applicability to the clinical setting. Ann Surg. (2008) 247:583-602. doi: 10.1097/SLA.0b013e3181656ce9

52. Weibel S, Jokinen J, Pace NL, Schnabel A, Hollmann MW, Hahnenkamp K, et al. Efficacy and safety of intravenous lidocaine for postoperative analgesia and recovery after surgery: a systematic review with trial sequential analysis. Br J Anaesth. (2016) 116:770-83. doi: 10.1093/bja/aew101

53. Willingham FF, Brugge WR. Taking NOTES: translumenal flexible endoscopy and endoscopic surgery. Curr Opin Gastroenterol. (2007) 23:550-5. doi: 10.1097/MOG.0b013e32828621b3
54. Wolthuis AM, Meuleman C, Tomassetti C, D’Hooghe T, Fieuws S, Penninckx F, et al. Laparoscopic sigmoid resection with transrectal specimen extraction: a novel technique for the treatment of bowel endometriosis. Hum Reprod. (2011) 26:1348-55. doi: 10.1093/humrep/der072

55. Leung KL, Lai PB, Ho RL, Meng WC, Yiu RY, Lee JF, et al. Systemic cytokine response after laparoscopic-assisted resection of rectosigmoid carcinoma: a prospective randomized trial. Ann Surg. (2000) 231:50611. doi: 10.1097/00000658-200004000-00008

56. Akiyoshi T, Kuroyanagi H, Oya M, Konishi T, Fukuda M, Fujimoto Y, et al. Short-term outcomes of laparoscopic rectal surgery for primary rectal cancer in elderly patients: is it safe and beneficial? J Gastrointest Surg. (2009) 13:1614-8. doi: 10.1007/s11605-009-0961-0

57. Nishimura A, Kawahara M, Suda K, Makino S, Kawachi Y, Nikkuni K. Totally laparoscopic sigmoid colectomy with transanal specimen extraction. Surg Endosc. (2011) 25:3459-63. doi: 10.1007/s00464-011-1716-Z

58. Ma B, Huang XZ, Gao P, Zhao JH, Song YX, Sun JX, et al. Laparoscopic resection with natural orifice specimen extraction vs. conventional laparoscopy for colorectal disease: a meta-analysis. Int J Colorectal Dis. (2015) 30:1479-88. doi: 10.1007/s00384-015-2337-0

Conflict of Interest Statement: The authors declare that the research was conducted in the absence of any commercial or financial relationships that could be construed as a potential conflict of interest.

Copyright (C) 2019 Liu, Zhang, Fan, Pei, Zhang and Dai. This is an open-access article distributed under the terms of the Creative Commons Attribution License (CC $B Y)$. The use, distribution or reproduction in other forums is permitted, provided the original author(s) and the copyright owner(s) are credited and that the original publication in this journal is cited, in accordance with accepted academic practice. No use, distribution or reproduction is permitted which does not comply with these terms. 